\title{
Susceptibility of Anopheles Mosquito to Agricultural Insecticides in the Adansi North District, Ghana
}

\author{
Nicholas A. Egyir ${ }^{1,2}$, Bernard Walter L. Lawson ${ }^{1}$, Kwame Desewu ${ }^{2}$, Rosemary \\ Ampofo-Bekoe ${ }^{2}$, Hezekiel M. Kumalo ${ }^{3}$ and Daniel G. Amoako ${ }^{4,5 *}$ (D)
}

${ }^{1}$ Department of Environmental Science, College of Science, Kwame Nkrumah University of Science and Technology, Kumasi, Ghana. ${ }^{2}$ Entomology Research Unit, Monitoring and Evaluation Department, AngloGold Ashanti (Ghana) Malaria Control Ltd, Obuasi, Ghana. ${ }^{3}$ Discipline of Medical Biochemistry, School of Laboratory Medicine and Medical Science, University of KwaZulu-Natal, Durban, South Africa. ${ }^{4}$ Discipline of Pharmaceutical Sciences, School of Health Sciences, University of KwaZulu-Natal, Durban, South Africa. ${ }^{5}$ Biomedical Resource Unit, School of Laboratory Medicine and Medical Sciences, College of Health Sciences, University of KwaZulu-Natal; Durban, South Africa.

\begin{abstract}
This study determined the susceptibility of Anopheles mosquitoes to some agricultural insecticides used in the Adansi North District of the Ashanti Region, and the efficacy of Actellic (pirimiphos-methyl) $50 \mathrm{EC}$ as an alternative insecticide for the control of mosquitoes in the district. Anopheles larvae were collected from mosquito breeding sites near farms. Five insecticides were assayed, pirimiphos-methyl $(0.9 \%)$, DDT (4\%), propoxur $(0.1 \%)$, deltamethrin $(0.05 \%)$, and lambda-cyhalothrin $(0.05 \%)$. The residual efficacy of pirimiphos-methyl $50 \mathrm{EC}$ sprayed on two surfaces (mud and cement) were determined by cone bioassay test at two-weekly intervals for 15 weeks after spraying. The susceptibility test showed the levels of phenotypic resistance of Anopheles spp. to the agricultural insecticides. Anopheles gambiae s.I. (96.50\%) was the most dominant Anopheles species. The principal malaria vector in the district was resistant to DDT, Propoxur, Deltamethrin, and Lambda-cyhalothrin. Pirimiphos-methyl an organophosphate remained effective against the malaria vector. Student t-test analysis of bioassay test results showed that statistically the average mortality of Anopheles mosquitoes on cement surface was higher than the average mortality on mud surface. In conclusion, agricultural insecticides used in the district were negatively affecting malaria vector control activities. The use of pirimiphos-methyl (Actellic $50 \mathrm{EC}$ ) as an alternative insecticide against the malaria vector was more effective on cemented wall surface than on mud surface wall.
\end{abstract}

Keywords: Susceptibility, Anopheles mosquito, insecticides, Adansi, Ghana.

*Correspondence: dasticky2010@gmail.com

(Received: 24 January 2019; accepted: 03 March 2019)

Citation: Nicholas A. Egyir, Bernard Walter L. Lawson, Kwame Desewu, Rosemary Ampofo-Bekoe, Hezekiel M. Kumalo and Daniel G. Amoako*, Susceptibility of Anopheles Mosquito to Agricultural Insecticides in The Adansi North District, Ghana, J Pure Appl Microbiol., 2019; 13(2): 677-688. doi: 10.22207/JPAM.13.2.04

(c) The Author(s) 2019. Open Access. This article is distributed under the terms of the Creative Commons Attribution 4.0 International License which permits unrestricted use, sharing, distribution, and reproduction in any medium, provided you give appropriate credit to the original author(s) and the source, provide a link to the Creative Commons license, and indicate if changes were made. 


\section{INTRODUCTION}

The population of Africa has increased in the last three decades and has resulted in increasing demand for food. This increasing population cannot be sustained without the use of pesticides in food production (Hazell \& Wood 2008). Pesticides are used to reduce food losses not only during production, but also during the post-harvest storage stage. Different classes of insecticides are used in agricultural production. The common ones used are the organic insecticides which include organochlorines, organophosphates, carbamates and pyrethroids (Aktar et al. 2009). The general pest control strategy is to destroy the pests feasting on the crops, but at the same time not to damage the produce so much as to render them unhealthy or unprofitable. Insecticides may leave toxic residues on food and fodder which may have adverse effects on the ecosystem by creating disequilibrium of food chains, scavengers, insect-host and insect-plant relationships. There is a danger that insecticides may kill organisms other than the targeted insects (Moy \& Wessel 2000).

Vector control remains the most effective strategy of malaria control and the two most important control strategies are the use of longlasting insecticide-treated nets (LLINs) and indoor residual spraying (IRS) which have helped reduce malaria mortalities in Africa by $33 \%$ in the last decade (Hemingway 2014). However, the World Health Organisation (WHO) has recommended the use of these same classes of insecticides in public health activities such as treating of longlasting mosquito nets, indoor residual spraying and larviciding. The Global Plan for Insecticide Resistance Management (GPIRM) was launched in 2012 in response to the danger of insecticide resistance which could lead to the failure of vector control interventions (WHO 2013). The use of chemical insecticides to control malaria vector as well as the use of these same insecticides in agriculture may contribute to the development of resistance (Yadouleton et al. 2009). The New Partnership for Africa's Development (NEPAD) in 2013 reported that there has been an increased utilisation of agricultural insecticides and has resulted in major reduction in harvest losses. Insecticides move through the environment; thus, the use of insecticides to control pests in agriculture has become a threat to malaria vector control (Diabate et al. 2002). The continuous utilisation of these chemicals is detrimental to humans and other life forms. There is also the risk of insecticide resistance which will lead to widespread failure of public health interventions.

Agriculture is the backbone of Ghana's economy. It accounts for $29.9 \%$ of the Gross Domestic Product (GDP) of Ghana (Ghana Statistical Service 2010). Recent studies on the continuous use of insecticides in food production in the country to increase productivity and maximise profit has been reported (Elvis Asare 2015; Denkyirah et al. 2016). Hence there is the need for an evidence-based study to evaluate the susceptibility of the malaria vector to families of chemical insecticides utilised in malaria control interventions and in agriculture. This study sought to determine the susceptibility of Anopheles mosquito to some agricultural insecticides which are also used in public health for the control of mosquitoes at the Adansi north district, in the Ashanti Region of Ghana.

\section{MATERIALS AND METHODS}

\section{Study area and geographical location}

The study was conducted in the Adansi North District which covers an area of approximately $1140 \mathrm{~km}^{2}$ representing about $4.7 \%$ of the total land area of Ashanti Region in Ghana. The district is located between Longitude 1.50W, latitude $1.4 \mathrm{~N}$ and Longitude $1.50 \mathrm{~W}$ latitude 6.30 $\mathrm{N}$ within the semi-equatorial climatic region and thus experiences high temperatures and high rainfall throughout the year (Ghana Statistical Service 2010). A map of the study area is shown in Fig. 1. It is one of the major cereals, cash crop and vegetable production centres in Ghana; these crops are produced both for local consumption and for export. Out of the total of the 23863 households in the district, $74.2 \%$ of them are engaged in various types of agricultural activities (Ghana Statistical Service 2010) and as a result they resort to the use of any means at their disposal to prevent pest infestation, obtain higher yields, and avoid post-harvest losses in their farming activities.

\section{Questionnaire administration}

A questionnaire was administered to obtain information on knowledge and extent of insecticide usage by farmers and the crops grown in the district with the assistance of Agricultural 
Extension officers. A total of 300 farmers were covered. Multiple answers were allowed.

Collection and identification of mosquitoes

Anopheles larvae were collected from mosquito breeding sites near farms. Anopheles larvae were identified by their parallel position on the water surface. Water containing mosquito larvae was collected using a ladle, into labelled plastic containers with lids and transported to the insectary of AngloGold Ashanti (Ghana) Malaria Control Ltd in Obuasi. A total of 3500 wild female Anopheles spp. and 2700 susceptible Anopheles spp. (Kisumu strain) were used for the study. Morphological identification of mosquitoes was done using the taxonomic keys of Gillies \& Coetzee (1987).

\section{Rearing of mosquito larvae to adulthood}

Mosquito larvae collected from breeding grounds were sent to the insectary and transferred into plastic bowls of about $2 \mathrm{~cm}$ depth and labelled to denote the breeding site and date of collection. Larvae were fed twice daily with fish meal and closely monitored till pupation when pupae were collected into adult mosquito cages. The average temperature and relative humidity of the adult mosquito room of the insectary were $26.4^{\circ} \mathrm{C}$ and $80.6 \%$, respectively. Adult mosquitoes were fed with $10 \%$ sugar solution, soaked in cotton balls.

\section{Adult mosquito susceptibility bioassays}

Susceptibility of Anopheles mosquito was determined using the standard WHO protocol. There were two tubes marked red and green representing exposure and holding tubes respectively (WHO 2013). The red marked tubes had impregnated insecticide papers held in the tube with copper clips whilst the holding tubes had plane paper held in place by steel clips. The slide unit with $20 \mathrm{~mm}$ hole was then fixed to the holding tube. Anopheles mosquito were introduced into the holding tubes through the $20 \mathrm{~mm}$ opening using the straight aspirator. Twenty to twenty-five active female mosquitoes were aspirated from a mosquito cage into each of the six holding tubes. Mosquitoes were kept in the holding tubes for one hour, after which they were transferred into the exposure tubes. The exposure tube was fixed to the slide unit of the holding tube and mosquitoes were transferred into their corresponding exposure tubes (WHO 2013). Non-blood fed female Anopheles mosquitoes that were 3-5 days old were tested with the five insecticides; Pirimiphos methyl (0.9\%), DDT (4\%), Propoxur $(0.1 \%)$, Deltamethrin $(0.05 \%)$, and Lambda-cyhalothrin $(0.05 \%)$. Knockdown rates were recorded at 5, 10, 15, 20, 30, 40, 50 and 60 min after which the mosquitoes were transferred back into the holding tubes. A pad of cotton-wool soaked in $10 \%$ sugar water that served as food was placed on the mesh-screen end of the holding tubes and allowed to stand upright for 24 hours (WHO 2013). Laboratory maintained Anopheles sp. (Kisumu strain) known to be susceptible to all the

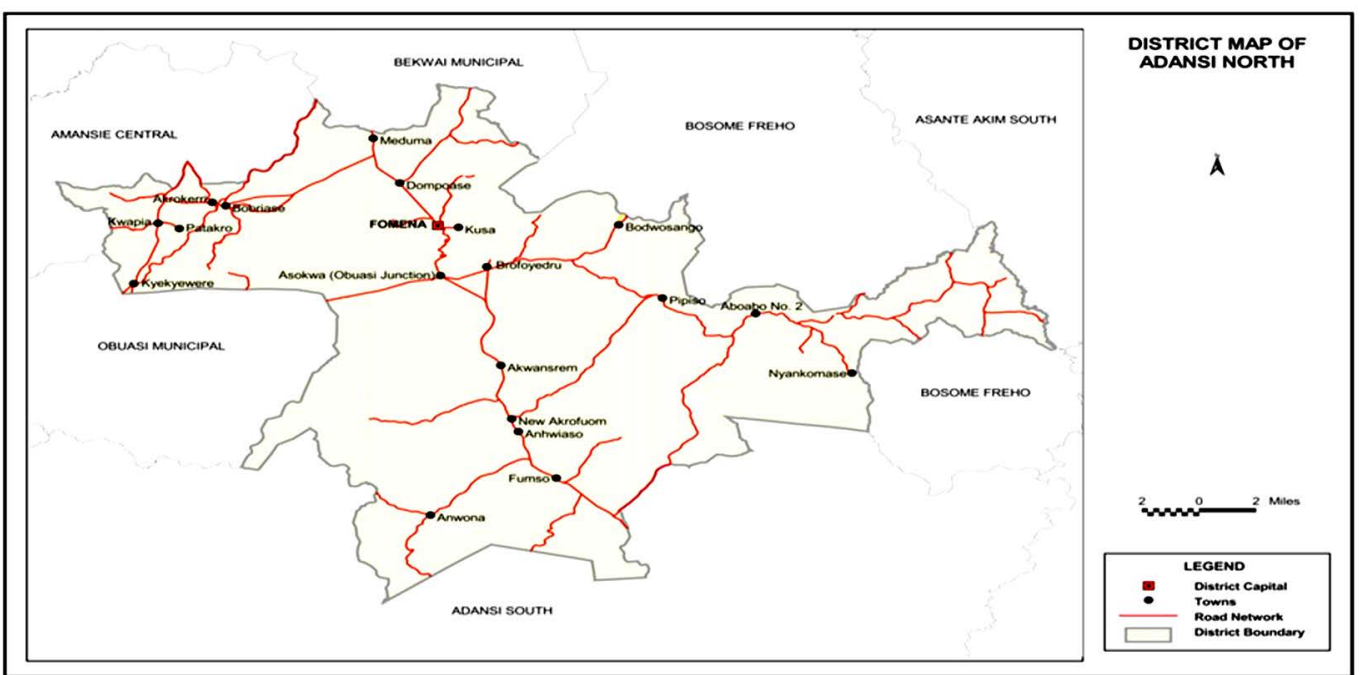

Fig. 1. Map of the study area, Adansi North District, Ashanti Region. 
insecticides being tested was used as a reference strain. Mortalities were recorded after 24 hour post-exposure, according to the formula below:

Observed mortality $=($ Total number of dead mosquitoes)/ (Total sample size) x 100

Indoor residual spraying application

Actellic 50 EC (Syngenta) with pirimiphosmethyl as active ingredient was selected and its efficacy on emulsion painted cemented surface and mud walled surface evaluated. Actellic 50 EC was obtained from the operations department of AngloGold Ashanti (Ghana) Malaria Control Ltd. A 10 litre spray pump was used. One litre of Actellic 50 EC was mixed in 9 litres of tap water in the spray can and pressurised to $379.2 \mathrm{kPa}$ (Syngenta 2005). The application rate was 4.5 seconds. One emulsion-painted cemented surface and one mud surface houses were chosen from each of the four communities, Pipiiso, Bodwesango, Tewobaabi and Old Edubiase.

\section{Efficacy monitoring of Actellic 50 EC}

The efficacy monitoring on the two surfaces were assessed by the cone bioassay test. The mortality rate of Anopheles mosquito to the insecticide sprayed on the two surfaces were monitored at two-weekly intervals for 15 weeks after spraying, from 3 January, to 5 April 2015. The edges of the transparent plastic cones were lined with adhesive tapes at three different points on the surfaces and these were the top, centre and bottom. Another cone was fixed on insecticidefree board and used as control. Ten 3-5-day old non-blood fed adult female Anopheles mosquitoes which were obtained through larval collection and reared in the insectary were transferred into the transparent cone fixed on the wall and observed for 30 min at 5, 10, 15, 20 and 30 min for "knocked downs". Separate aspirators were used to transfer mosquitoes to control cones. After the $30 \mathrm{~min}$, the mosquitoes were carefully transferred from the cones to separate paper cups. A pad of a cottonwool soaked in $10 \%$ sugar water was placed on the mesh-screen end of the paper cups to provide feed for the adults and held for $24 \mathrm{~h}$. Laboratorymaintained Anopheles sp. (Kisumu strain) known to be susceptible to all the insecticides being tested was used as a reference strain. The numbers of dead mosquitoes were counted after $24 \mathrm{~h}$. Percentage mortality was calculated, and the mosquitoes were identified morphologically to species level (Gillies \& Meillon 1968).

\section{Data analysis}

The questionnaire data was analysed and presented in Tables, Charts and percentages using SPSS version 16 software. Test data were interpreted as: death rate between 98 and 100\% shows susceptibility; death rate of between $90 \%$ and $97 \%$ was suggestive of the presence of resistance and further examination was required; death rate under $90 \%$, affirmed resistance (WHO 2013). Analysis of variance (ANOVA) was used to analyse the efficacy monitoring data at $5 \%$ significance level. Student $t$-test analysis compared average mortalities on the emulsion painted cement surface and the mud surface and $F$-statistic compared the average mosquito mortalities in the four communities.

Table 1. Major insecticides used in the Adansi North District by farmers

\begin{tabular}{|c|c|c|c|c|}
\hline S.No. & Brand Name & Active Chemical & Content & $\begin{array}{l}\text { Class of } \\
\text { Insecticide }\end{array}$ \\
\hline 1 & Confidor $200 \mathrm{SL}$ & Imidacloprid & $200 \mathrm{~g} / \mathrm{l}$ & Neonicotinoid \\
\hline 2 & Actara 240 SC & Thiamethoxam & $240 \mathrm{~g} / \mathrm{l}$ & Neonicotinoid \\
\hline 3 & $*$ DDT & $p, p^{\prime}-D D T$ & & Organochlorine \\
\hline 4 & Akatse Master & Bifenthrin & $27 \mathrm{~g} / \mathrm{l}$ & Pyrethroid \\
\hline 5 & Karat 5 EC & Lambda-cyhalothrin & $(240 \mathrm{~g} / \mathrm{l})$ & Pyrethroid \\
\hline 6 & Lambda Super 2.5 EC & $\begin{array}{l}\text { Lambda-cyhalothrin } \\
\text { + dimethoate }\end{array}$ & $36 \mathrm{~g} / \mathrm{l}, 36 \mathrm{~g} / \mathrm{l}$ & Pyrethroid \\
\hline 7 & Lambda - M 2.5\% EC & Lambda-cyhalothrin & $25 \mathrm{~g} / \mathrm{l}$ & Pyrethroid \\
\hline 8 & Actellic 50 EC & Pirimiphos-methyl & $50 \mathrm{~g} / \mathrm{l}$ & Organophosphate \\
\hline 9 & Sumitox EC & Fenvalerate & $200 \mathrm{~g} / \mathrm{l}$ & Pyrethroid \\
\hline
\end{tabular}

*DDT is no longer registered for use in Ghana but it is still being used by some farmers. 


\section{RESULTS}

\section{Questionnaire survey}

A total of 300 farmers from 23 communities in the study area took part in the questionnaire survey. Among the farmers, 206 (68.7\%) were males and 94 (31.3\%) were females. Ninety-five percent $(95 \%)$ of respondents had at least 3 years of experience in the use of agricultural insecticides. Sixty-eight percent $(68$ $\%$ ) of respondents had not been to school, $21 \%$ had education up to the primary school level, 10 $\%$ had a secondary school level education and only $1 \%$ had education to the tertiary level.

Insecticides used for crop protection against insect pests

Neonicotinoids were the largest class of insecticides used by farmers in the study district accounting for $47 \%$ of all insecticide family used. Pyrethroids, organophosphates and organochlorines represented 33.9\%, 13.2\% and $5.9 \%$, respectively. Pyrethroids were mainly bifenthrin, lambda-cyhalothrin and fenvalerate whilst the organophosphate was pirimiphosmethyl. Fenvalerate was the least used insecticide (8.1\%), far lower than the utilisation rate of imidacloprid and bifenthrin with utilisation rates of $73.5 \%$ and $47.0 \%$ respectively (Fig. $2 a$ ).

Insecticides used and their status

Farmers in the district rely heavily on insecticides for the control of insect pests (Supplementary Table S1-3 and Fig. S1). An organochlorine, DDT, found in use in the area (Table 1 ) is not registered for use in Ghana because there are safer alternatives and also because of its persistence in the environment. Up to $62 \%$ of respondents do not understand the labels on the insecticides. On dosage of insecticides, it was noticed that only a few adhered to the recommended dose. Most of the farmers (52\%), reported that they lack knowledge
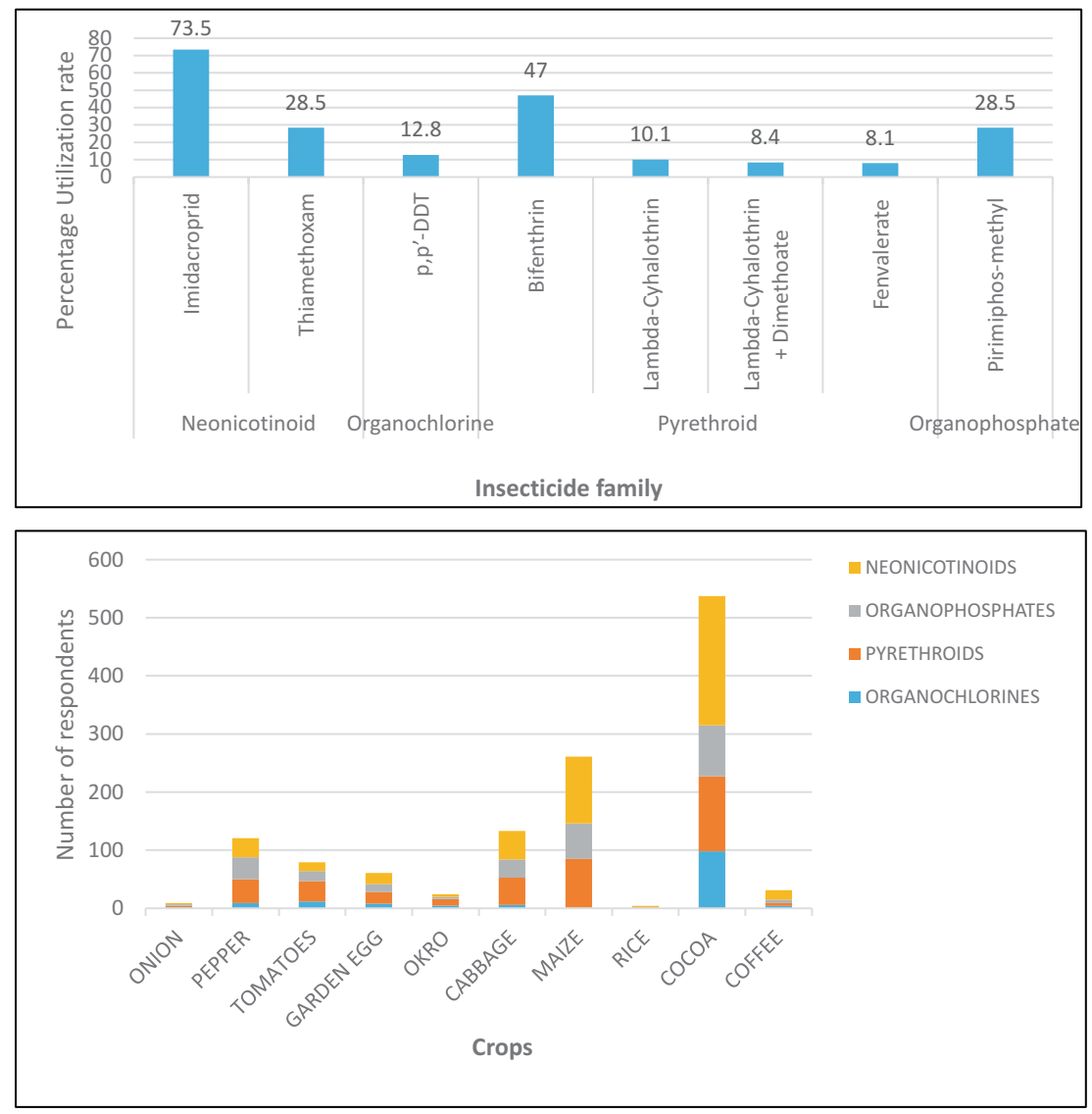

Fig. 2a. Utilization rate of the various families of insecticides. $\mathbf{2 b}$ : Distribution of insecticide class used by the farmers to spray crops. 
or understanding of what dosage of insecticide means; thus most of the respondents misused and applied chemicals indiscriminately. Ninetyeight percent of the respondents do not use insecticides in controlling pests in their homes, however, $2 \%$ used insecticides in their homes to control cockroaches, ants, and other domestic insects because they were effective in killing these domestic pests. Some of the farmers (29\%) reported that they usually experience discomfort after spraying their crops; they attributed their discomfort to the use of insecticides. The frequency distribution of the insecticide class used by the farmers (Fig. 2b) to spray crops in a single crop season.

\section{Vector susceptibility test}

The results for the susceptibility status of Anopheles spp. is presented in Fig. 3a below and Anopheles spp. was considered resistant to four out of five insecticides tested. The two insecticides belonging to the pyrethroid class, namely, lambdacyhalothrin and deltamethrin recorded $52 \%$ and $41 \%$ mortality respectively. There was $3 \%$ mortality rate for mosquitoes exposed to DDT. Propoxur recorded $46 \%$ mortality. The highest (99\% mortality) susceptibility was observed for pirimiphos methyl, an organophosphate (Table S4). Knockdown rates (Fig. 3b) for all the insecticides assayed were obtained after one-hour exposure of adult Anopheles mosquito to insecticide-treated
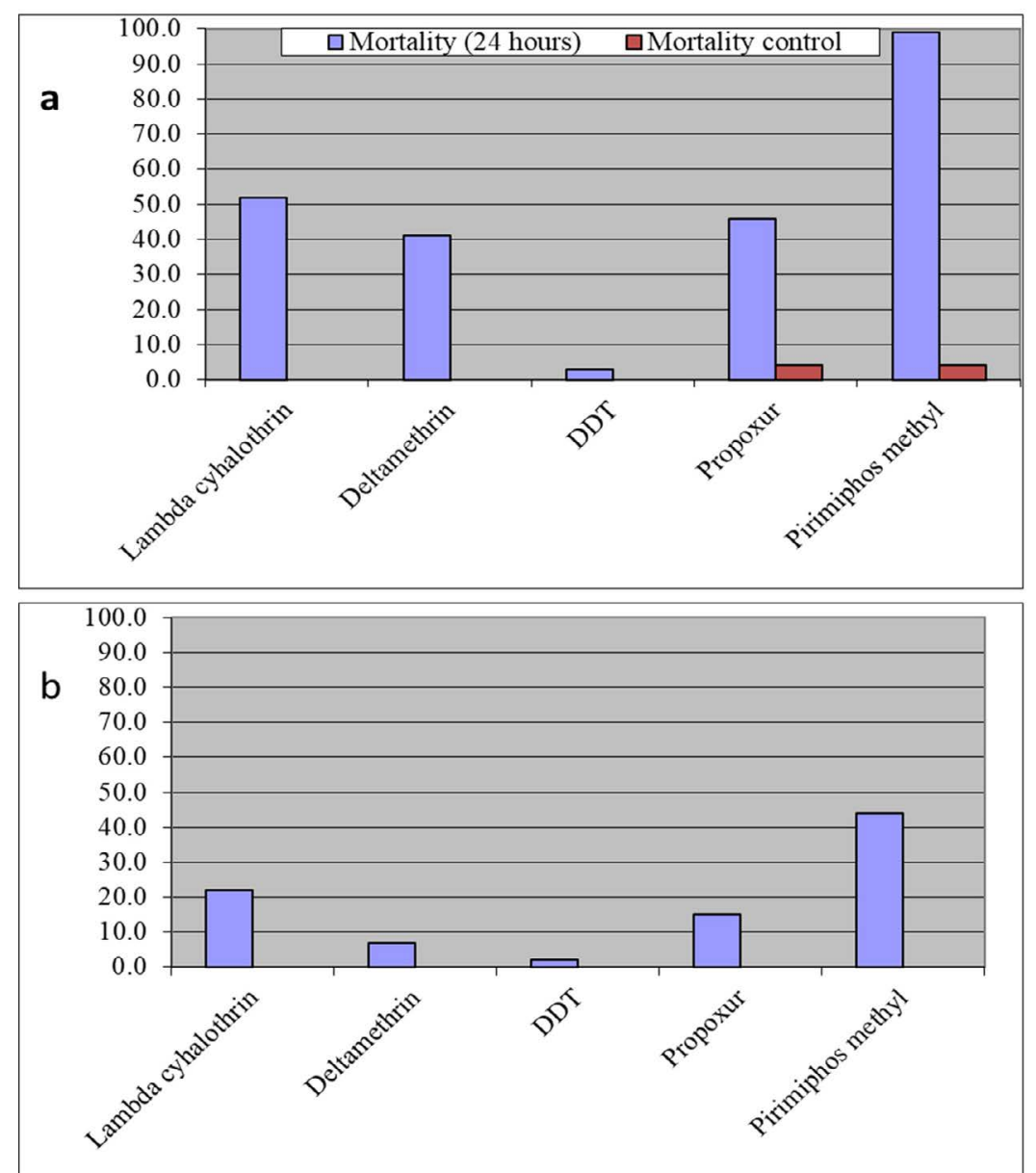

Fig. 3a Susceptibility of Anopheles spp. to insecticides used for crop protection in the study district. The blue bar represents mortalities in test groups and the orange bar mortalities in control groups. Control mortality MT24 was less than 10\%, thus no correction required (Control MT24 =4\%). 3b: Knockdown rates for all insecticides assayed. The knockdown rates for all the insecticides assayed were obtained after one-hour exposure of adult Anopheles mosquitoes to the insecticide-treated papers. 
papers. Fig. S2-11, show graphs of knockdowntime curve for all insecticide assayed.

\section{Cone bioassay test}

The residual efficacy monitoring test showed pirimiphos-methyl remained effective against the vector. From week one to seven, the average percentage mortalities after $24 \mathrm{~h}$ of examination were $100 \%$ and $52.5 \%$ for cemented and mud surfaces respectively (Fig. 4a). However, at week 15, the average percentage mortalities were $93.33 \%$ for cemented surface and $21.67 \%$ for mud surface. Fig. $4 \mathrm{~b}$ shows the average percentage mortalities $24 \mathrm{~h}$ post exposure between the wild and susceptible Anopheles strain.

Dominant Anopheles species in the district

Anopheles species identified on the basis of morphological features on the adult showed that Anopheles gambiae s.I (96.50\%) was dominant Anopheles spp. in the area followed by Anopheles funestus (3.00\%) and Anopheles pharoensis (0.50\%).

\section{DISCUSSION}

Insecticides used by farmers are, incidentally, the same as those recommended for use in the control of the malaria vector mosquitoes. Thus, there is a threat of mosquito vector resistance to the insecticides used to control it. The use of pesticides is the principal pest control strategy commonly applied by farmers to protect their crop in the district. These products, if not used correctly, can have direct environmental and health consequences and indirect consequences through the selection of insecticide resistance in
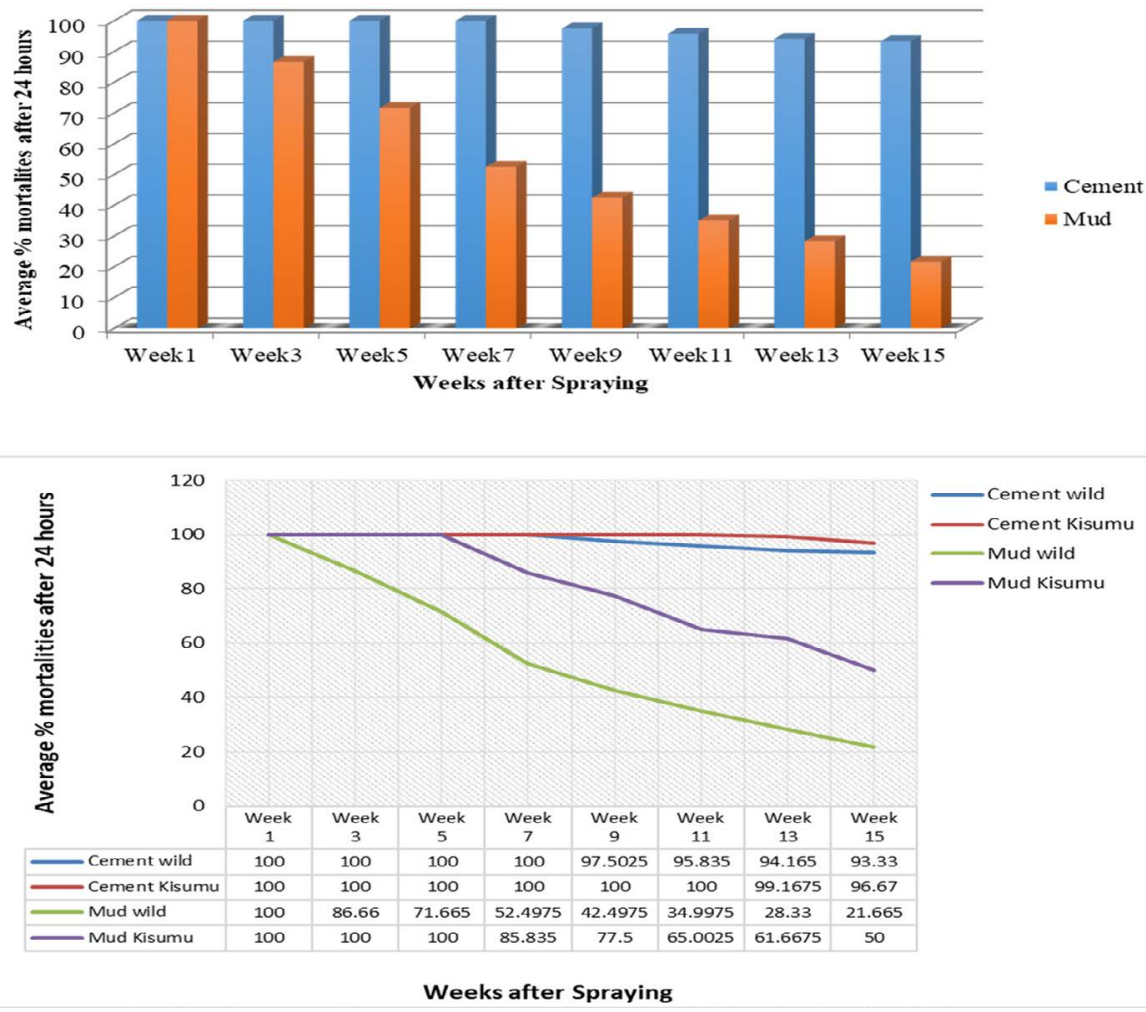

Fig. 4a: Exposure time mortality bioassay of wild Anopheles spp. with Actellic 50 EC on two surfaces (cemented and emulsion painted, and mud). Mortality rates were obtained after 30 minutes of exposure of adult Anopheles mosquitoes to the sprayed surface and 24 hour holding period. 4b: Exposure time mortality bioassay of Anopheles spp. and Susceptible Anopheles spp. (Kisumu strain) with Actellic 50 EC on two surfaces (cemented and emulsion painted, and mud). Mortality rates were obtained after 30 minutes of exposure of adult Anopheles mosquitoes to the sprayed surface and 24 hour holding period. Student T-test analysis of average mortality rate for cement surfaces and mud surfaces result showed that average mortality of $97.6 \%$ for cement surfaces and $54.8 \%$ for mud surfaces was significant $(P$-value $>0.05)$. 
malaria vectors. This constitutes a real threat for insecticide-based vector control and can lead to vector-control intervention failures, as reported by Hargreaves et al. 2000 in South Africa.

Results from this study, indicated that there was heavy reliance on some specific insecticides. Neonicotinoid were the class of insecticides most used by farmers in the district. These accounted for $47.0 \%$ of all insecticides used. Insecticide residues may contaminate soil and mosquito breeding water. This may create a strong selective pressure in mosquito larvae breeding sites (Hien et al. 2017). It was observed that the rate of application was not in agreement with both the manufacturers and Ministry of Agriculture recommendations. "Akatse master" (with Bifenthrin as the active ingredient) recommended for use on cocoa is used for vegetable and cereal cultivation. Cocoa should be sprayed once every month for 8 months but most of the farmers applied chemical insecticides 3 times (minimum) and 12 times (maximum) application rates. This means most farmers do not even understand pest biology, including susceptibility or resistance levels to chemicals used. Thus, a potential development of resistance in the pests was likely to be interpreted as an insecticide under-dosing, which may lead to an increase in insecticide application (Stratonovitch et al. 2014).

Majority of the respondents ( $68 \%$ ) could not read nor write and thus could not understand labels on insecticide containers (Jepson et al. 2014). Ajayi \& Akinnifesi 2007, concluded from a study that most farmers did not understand pesticide safety labels and instructions on field spraying practices, thus limiting the potential for written information on chemicals to be used accurately, with resultant serious environmental and health consequences. About $29 \%$ of farmers complained about headache, nausea and vomiting after insecticide application which is consistent with findings from field study by Clarke et al. (1997). The study explained further that there were direct linkages between knowledge and/ or the use of protective equipment by farmers on the one hand and the extent of negative side effects on the other hand (Clarke et al. 1997). The Ministry of Agriculture in the district has also not done enough to educate farmers on the choice of insecticide, the dosage and the dilution rate. This has led to farmers buying insecticides from local agrochemical shops and using their own dilution and application rates. Even though DDT was banned by the EPA, some farmers still acquired it illegally due to an uncontrolled sales and distribution of insecticides in the district by agrochemical sellers. Uncontrolled use of agricultural insecticides may lead to the contamination of larval breeding sites (Hien et al. 2017). The metabolic system of the mosquito could be affected which could lead to development of tolerance of adult mosquitoes to several insecticides and selection for resistance over several generations (Nkya et al. 2014). The use of different classes of chemical insecticides in agriculture, could lead to much faster development of resistance by the malaria vector (Ajayi \&Akinnifesi 2007). Nkya et al. (2014) reported that, Anopheles gambiae larvae that were exposed to a mixture of agricultural insecticides increased their resistance to a broad range of insecticides at the adult stage.

The present study has shown that practices of farmers in the district may favour the development of resistance in malaria vectors as indicated by Antonio-Nkondjio et al. (2011) and Yadouleton et al. (2009). The susceptibility test showed the levels of phenotypic resistance of Anopheles spp to agricultural insecticides. The principal malaria vector in the study area was resistant to Lambda-cyhalothrin, Deltamethrin, DDT and Propoxur. Pirimiphos-methyl, an organophosphate, was, however, effective against the vector. Anopheles spp. were highly resistant to DDT. One may expect that the malaria vector should have regained its susceptibility to DDT after its use commercially had been banned for a very long time; this was, however, not the case. Responses from the farmers showed that some quantities were still acquired and subtly used. DDT and pyrethroids have the same mode of action, thus, the $3 \%$ mortality recorded could be attributed to the phenomenon of cross-resistance (Macoris et al 2018). This confirms the findings that population of insects that were resistant to DDT in the 1950's also exhibited resistance, with no previous exposure to pyrethroid insecticides used decades later (WHO 1992). The World Health Organization has recommended pyrethroids for treating mosquito nets which has become 
the main method of malaria prevention in Ghana. Uncontrolled utilization of agricultural insecticides for crop protection and higher yields may support development of resistance. This trend has the tendency to negatively affect the control of the malaria vector. The negative effects of agricultural insecticides could be reduced by enhancing farmers understanding and knowledge on the use and management of insecticides, including rotation of various classes of insecticides. Insecticide resistance admini-stration procedures support rotation of insecticide classes utilized in IRS and LLINs. Utilization of insecticides in IRS and LLINs in vector control is the major selective force. Nevertheless, if a significant proportion of selection pressure originates from agriculture, then rotational utilization of various classes of insecticides in IRS may just have a limited efficiency. Efficient resistance management depends not only on information about the insect population but also consideration of the main sources of insecticide resistance selection pressures (Helps et al. 2017). The increase in uncontrolled utilization of agricultural insecticides for crop protection and higher yields may support development of resistance. In this manner, the spread of insecticide resistance is most likely a result of both vector control and the increased use of agricultural insecticides.

Indoor residual spraying (IRS) strategy has a great impact on the transmission rate of malaria. IRS reduces the life span of mosquitoes, reduces the number of people bitten by mosquitoes and contributes to reduction of malaria transmission, mortality and morbidity (Steinhardt et al. 2013). Student T-test analysis of bioassay results showed that statistically the average mortality $(97.6 \%)$ on cement plastered surface was higher than the on mud-plastered surface (54.8\%). This result is consistent with that of Agossa et al. (2014). Actellic 50 EC could have been absorbed or broken down quicker on a mud surface than on the cemented surface. The mud surface had crevices and some of the insecticides may have gotten into these crevices and thus were unavailable on the surface. This could have contributed to the lower average mortality rates of $54.8 \%$ for mud surface over the period of the cone bioassay test.

\section{CONCLUSION}

In summary, the spread of insecticide resistance is most likely to come from agricultural insecticide usage and vector control programmes. There is, thus, an effect of agricultural insecticide usage on malaria vector control interventions. It is recommended that molecular studies be undertaken on the Anopheles species in the study area to determine the levels and mechanisms of resistance and to identify the Anopheles gambiae complex present in the district.

\section{ACKNOWLEDGEMENTS}

The authors thank the staff of the Ministry of Food and Agriculture (Adansi North District office), the people of the Adansi North district who welcomed us to their homes during the period of the study and the Entomology Research Unit, AngloGold Ashanti (Ghana) Malaria Control Ltd, Obuasi, Ghana for their assistance in the field and laboratory work.

\section{CONFLICT OF INTEREST}

The authors declares that there is no conflict of Interest.

\section{AUTHOR'S CONTRIBUTION}

$N E, B L, K D, R A, H K$ and DA Coconceptualised the study. NE and KD performed the laboratory work. NE KD and DA analyzed the data. NE, BL, KD, RA, HK and DA did vetting of results. NE wrote the manuscript. NE, BL, KD, RA, HK and DA Undertook critical revision of the manuscript.

\section{FUNDING}

None.

\section{DATA AVAILABILITY}

All datasets generated or analyzed during this study are included in the manuscript and/or the Supplementary Files.

\section{REFERENCES}

1. Agossa, F.R., A|kpon, R., Azond'kon, R., Govoetchan, R.,. Padonnou, G.G., Oussou, O., Ok'-Agbo, F. \& Akogb'to, M.C. Efficacy of various insecticides recommended for indoor residual spraying: Pirimiphos methyl, potential alternative to bendiocarb for pyrethroid resistance management in Benin, West Africa. Transactions of the Royal Society of Tropical Medicine and Hygiene, 
2014; 108: 84-91.

2. Ajayi, O.C. \& Akinnifesi, F.K. 2007. Farmers ' understanding of pesticide safety labels and field spraying practices/: a case study of cotton farmers in northern Cפte d' Ivoire. Scientific Research and Essays 2: 204-210. Aktar, W., Sengupta, D \& Chowdhury, A. Impact of pesticides use in agriculture: Their benefits and hazards. Interdisciplinary Toxicology, 2009; 2: $1-12$.

3. Antonio-Nkondjio, C., Fossog, B. T., Ndo, C., Djantio, B. M., Togouet, S. Z., Awono-Ambene, P., Costantini, C., Wondji, C. S. \& Ranson H. Anopheles gambiae distribution and insecticide resistance in the cities of Douala and Yaounde (Cameroon): Influence of urban agriculture and pollution. Malarial Journal, 10, 2011.

4. Clarke, E. E. K., Levy L.S., Spurgeon, A. \& Calvert. I. A. The problems associated with pesticide use by irrigation workers in Ghana. Occupational Medicine (Chic. III), 1997; 47: 301-308.

5. Denkyirah, E. K., Okoffo, E. D., Adu, D. T., Aziz, A. A., Ofori, A. \& Denkyirah E. K. Modeling Ghanaian cocoa farmers' decision to use pesticide and frequency of application: the case of Brong Ahafo Region. Springer plus. 2016; 5(1113).

6. Diabate, A., Baldet, T., Chandre, F., Akogbeto, M. , Guiguemde, T. R.,. Darriet, F., Brengues, C., Guillet, P., Hemingway, J., Small, G. J. \& Hougard J. M. The role of agricultural use of insecticides in resistance to pyrethroids in Anopheles gambiae s.l. in Burkina Faso. The American Journal of Tropical Medicine and Hygiene, 2002; 67: 617-622.

7. Elvis Asare, V. A. S. Pesticide Use Practices and Perceptions of Vegetable Farmers in the Cocoa Belts of the Ashanti and Western Regions of Ghana. Advances in Crop Science and Technology, 2015; 3:174.

8. Ghana Statistical Services. Ghana's Economic Performance: Summary Report of Final Results of Population and Housing Census, Accra, Ghana, 2010; page 7.

9. Gillies, M. \&Meillon, D. The Anophelinae of Africa south of the Sahara (Ethiopian zoogeographical region). Johannesburg, South Africa: South African Insitute of Medical Research, Publication No., 1968; 54, 1343.

10. Gillies, M. T., \& Coetzee, M. A Supplement to the Anophelinae of the South of the Sahara (Afrotropical Region). South African Insitute of Medical Research, 1987; 55, 1143.

11. Hargreaves, K., Koekemoer, L. L., Brooke, B. D., Hunt, R. H., Mthembu, J. \& Coetzee, M. Anopheles funestus resistant to pyrethroid insecticides in South Africa. Medical and Veterinary Entomology, 2000; 14: 181-189.

12. Hazell, P. \& Wood, S. Drivers of change in global agriculture. Philosophical Transactions of the Royal Society B., 2008; 363(1491): 495-515. PMID: 17656343.

13. Helps, J. C., Paveley, N. D., \& van den Bosch, F. Identifying circumstances under which high insecticide dose increases or decreases resistance selection. Journal of Theoretical Biology, 2017; 428, 153-167.
14. Hemingway, J. The role of vector control in stopping the transmission of malaria: threats and opportunities. Philosophical Transactions of the Royal Society B., 2014; 369(1645): 20130431-20130431.

15. Hien, A. S., Soma, D. D., Hema, O., Bayili, B., Namountougou, M., Gnankin', O., ... Dabir', K. R. Evidence that agricultural use of pesticides selects pyrethroid resistance within Anopheles gambiae s.l. populations from cotton growing areas in Burkina Faso, West Africa. PLOS ONE, 2017; 12(3), e0173098.

16. Jepson, P. C., Guzy, M., Blaustein, K., Sow, M., Sarr, M., Mineau, P. \& Kegley, S. Measuring pesticide ecological and health risks in West African agriculture to establish an enabling environment for sustainable intensification. Philosophical Transactions of the Royal Society B., 2014; 369: 20130491.

17. Macoris, M. D. L., Martins, A. J., Andrighetti, M. T. M., Lima, J. B. P., \& Valle, D. Pyrethroid resistance persists after ten years without usage against Aedes aegypti in governmental campaigns: Lessons from STo Paulo State, Brazil. PLOS Neglected Tropical Diseases,2018; 12(3): e0006390.

18. Moy, G. G. \& Wessel, J. R. Codex Standard for Pesticide Residues, Internatioanl Standards for Food Safety, Rees, N. Watson, D., (Eds) Aspen Publishers Inc. Gaithersburg, MD, USA, 2000; Page 215.

19. NEPAD African agriculture, transformation and outlook. NEPAD, November 2013, Johannesburg South Africa, 2013.

20. Nkya, T. E., Akhouayri, I., Poupardin, R., Batengana, B., Mosha, F., Magesa, S., Kisinza, W. \& David J. P. Insecticide resistance mechanisms associated with different environments in the malaria vector Anopheles gambiae: A case study in Tanzania. Malarial Journal, 2014; 13.

21. Steinhardt, L. C., Yeka, A., Nasr, S., Wiegand, R. E., Rubahika, D., Sserwanga, A., Filler, S. The Effect of Indoor Residual Spraying on Malaria and Anemia in a High-Transmission Area of Northern Uganda. The American Journal of Tropical Medicine and Hygiene, 2013; 88(5), 855-861.

22. Stratonovitch, P., Elias, J., Denholm, I., Slater, R., \& Semenov, M.A. An Individual-Based Model of the Evolution of Pesticide Resistance in Heterogeneous Environments: Control of Meligethes aeneus Population in Oilseed Rape Crops. PLOS ONE, 2014; 9(12): e115631.

23. Syngenta. Actellic_an effective broad-spectrum insecticide for the control of public health pests; SPH/ BEAM/4969/01.05. Switzerland. (www. syngenta. com), 2005, Last accessed on 21st November 2014.

24. WHO (World Health Organization). Vector resistance to pesticides. Control WECoVBa, Geneva,1992; 62.

25. WHO (World Health Organization). Test procedures for insecticide resistance monitoring in malaria vector mosquitoes. WHO Technical Report Series, 2013; 22.

26. Yadouleton, A. W. M., Asidi, A., Djouaka, R. F., Brama, J., Agossou, C.D. \& Akogbeto, M.C. Development of vegetable farming: A cause of the emergence of insecticide resistance in populations of Anopheles gambiae in urban areas of Benin. Malarial Journal, 2009; 8. 
Supplementary Data

Table S1. Frequency distribution of class of insecticide used

\begin{tabular}{lcc}
\hline Class & Frequency & Percentage \\
\hline Neonicotinoid & 244 & 47.0 \\
\hline Organochlorine & 121 & 5.9 \\
Pyrethroid & 177 & 33.9 \\
Organophosphate & 101 & 13.2 \\
Total & 643 & 100 \\
\hline
\end{tabular}

Table S2. Rate of insecticide utilization in the district

\begin{tabular}{lccccc}
\hline Crops & Freq. & $\%$ & Min. & MAX. & Mean \\
\hline Onion & 4 & 1.3 & 3 & 3 & 3 \\
Pepper & 73 & 24.4 & 2 & 12 & 3.3 \\
Tomatoes & 56 & 18.7 & 2 & 12 & 3.3 \\
Garden Eggs & 29 & 9.7 & 2 & 12 & 4 \\
Okra & 12 & 4 & 3 & 12 & 5.7 \\
Cabbage & 61 & 20.1 & 2 & 20 & 4.1 \\
Maize & 134 & 44.8 & 1 & 4 & 2.3 \\
Rice & 1 & 0.3 & 4 & 4 & 4 \\
Cocoa & 257 & 86 & 1 & 12 & 4.8 \\
Coffee & 13 & 4.3 & 3 & 7 & 4.1 \\
Total & 639 & 213.7 & - & - & 3.86 \\
\hline
\end{tabular}

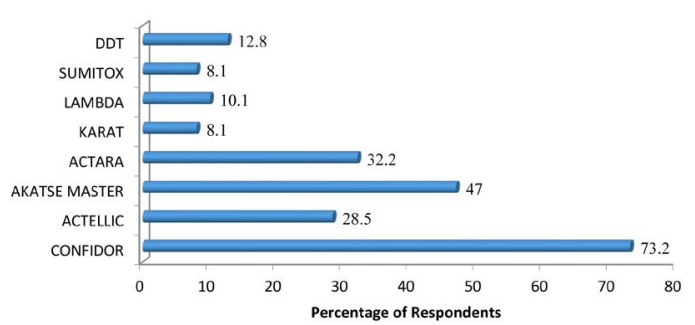

Fig. S1. Distribution of the insecticides used by the respondents to spray their crops

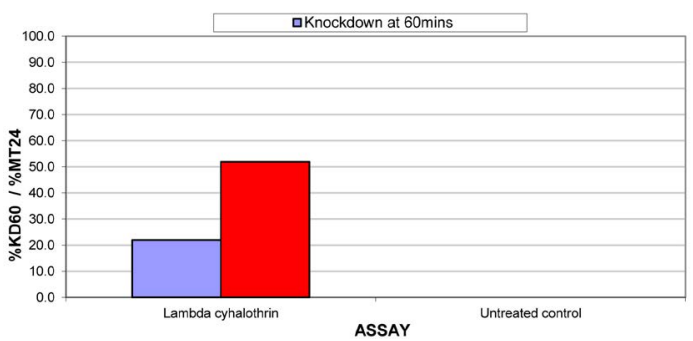

Fig. S2. Overall knockdown and mortality for Lambdacyhalothrin

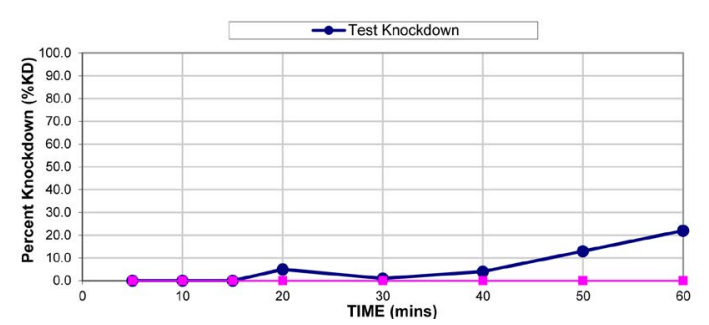

Fig. S3. Knockdown - Time Curve for Lambda-cyhalothrin

Table S3. Standard WHO susceptibility test with Anopheles spp. on insecticide-treated papers

\begin{tabular}{lcccccc}
\hline Insecticide & $\begin{array}{c}\text { Concentration } \\
(\%)\end{array}$ & $\begin{array}{c}\text { Knockdown } \\
\text { (60 mins) }\end{array}$ & $\begin{array}{c}\text { Control } \\
\text { knockdown }\end{array}$ & $\begin{array}{c}\text { Final test } \\
\text { mortality }\end{array}$ & $\begin{array}{c}\text { Control } \\
\text { mortality } \\
\text { (24 hours) }\end{array}$ & $\begin{array}{c}\text { Susceptibility } \\
\text { status }\end{array}$ \\
\hline Lambda-cyhalothrin & 0.05 & 22.0 & 0.0 & 52.0 & 0.0 & RESISTANT \\
Deltamethrin & 0.05 & 7.0 & 0.0 & 41.0 & 0.0 & RESISTANT \\
DDT & 4 & 2.0 & 0.0 & 3.0 & 0.0 & RESISTANT \\
Propoxur & 0.1 & 15.0 & 0.0 & 46.0 & 4.0 & RESISTANT \\
Pirimiphos- methyl & 0.9 & 44.0 & 0.0 & 99.0 & 4.0 & SUSCEPTIBLE
\end{tabular}




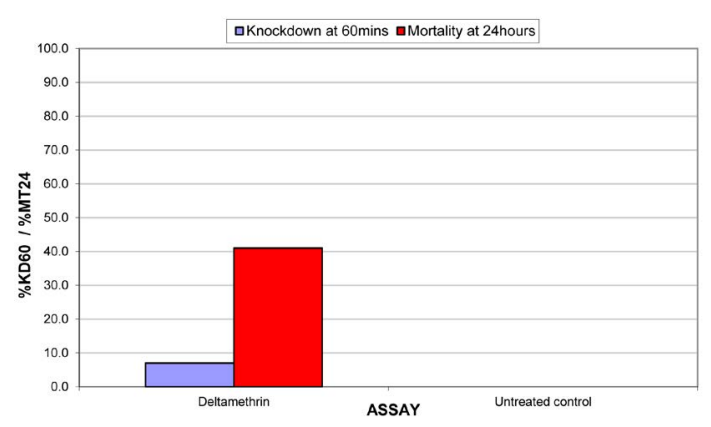

Fig. S4. Overall knockdown and mortality for Deltamethrin

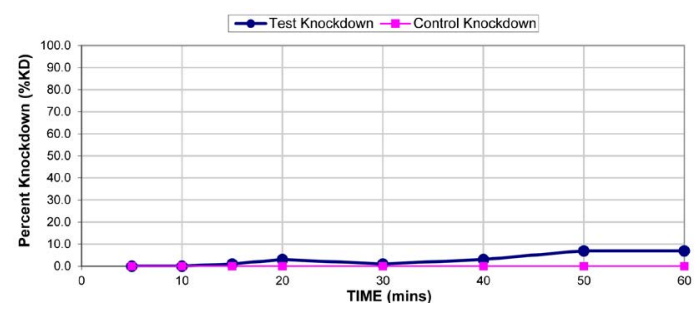

Fig. S5. Knockdown - Time Curve for Deltamethrin

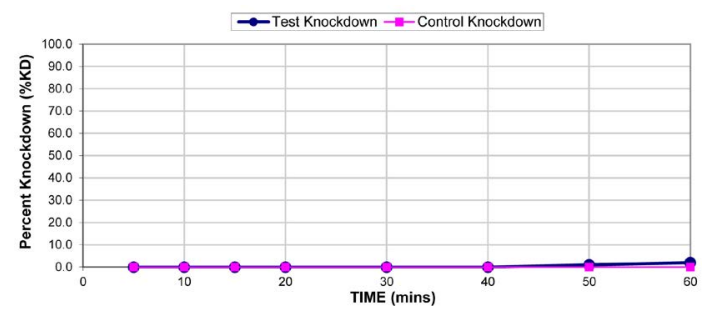

Fig. S6. Overall knockdown and mortality for DDT

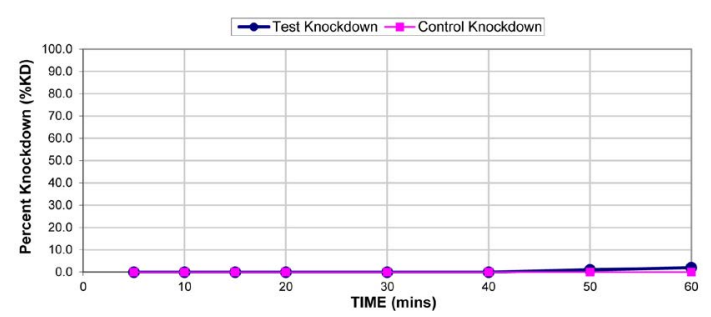

Fig. S7. Knockdown - Time Curve for DDT

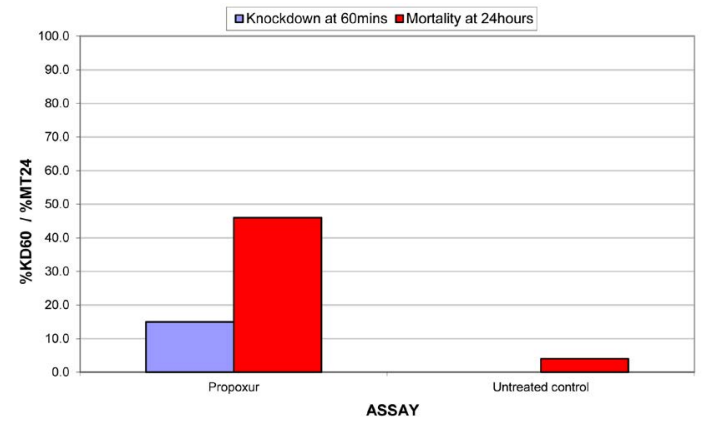

Fig. S8. Overall knockdown and mortality for Propoxur

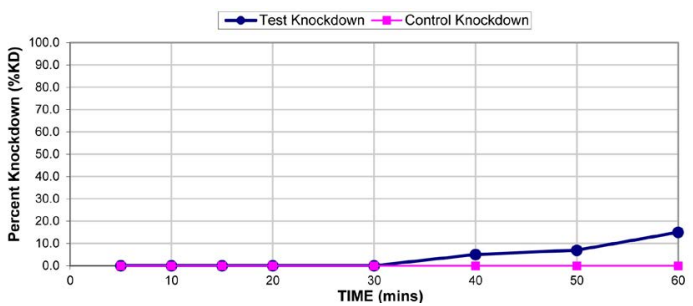

Fig. S9. Knockdown - Time Curve for Propoxur

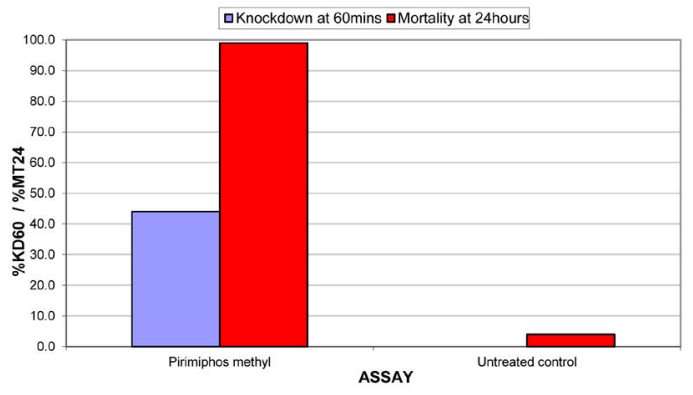

Fig. S10. Overall knockdown and mortality for Pirimiphos methyl

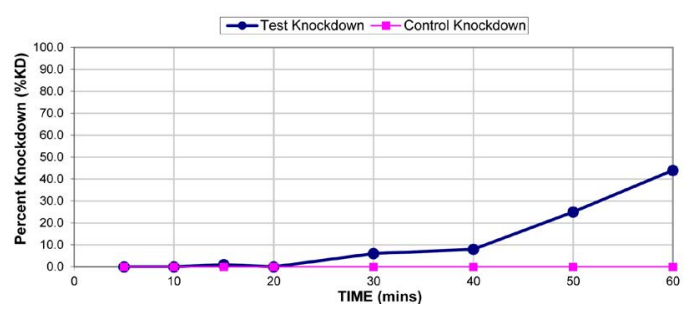

Fig. S11. Knockdown - Time Curve for Pirimiphos methyl 